\title{
Francisco Ayala. Un intelectual orteguiano de vuelta a casa
}

\author{
Francisco Ayala. An Orteguiano Intelectual Back Home*
}

ALESSIO PIRAS**

\begin{abstract}
Resumen: Después de la muerte de Franco, Francisco Ayala volvió definitivamente a España y se integró en la vida intelectual del país. En este artículo se pretende repasar cómo interpretó el granadino su papel de intelectual comprometido en la sociedad y de qué manera ha reinterpretado una parte del legado orteguiano en el periodo de la Transición. Se estudiará, pues, su labor intelectual en el marco del periodo transitorio a la democracia, enfocando este último con un planteamiento que rehúya las celebraciones enfáticas al igual que las críticas a priori.

Palabras clave: Transición, Ortega y Gasset, Francisco Ayala, Regreso, intelectual, Europa
\end{abstract}

\begin{abstract}
After Franco's death, Ayala back permanently to Spain and integrated into the intellectual day life of the country. The main goal of this article is to study how did Ayala interpret his role of compromised intellectual and in which way did he renew a part of José Ortega y Gasset political legacy during Spanish Transition. This paper is going to study, then, the intellectual work of Francisco Ayala during the Spanish Transition to democracy, and it will focus this historical period from a neutral point of view, avoiding both epic and catastrophic accounts.
\end{abstract}

Keywords: Transition, Ortega y Gasset, Francisco Ayala, Intelectual, Europe, Back Home

\section{1. ¿Qué es un intelectual orteguiano?}

Al hablar de Realidad, la revista que, entre otros, Francisco Ayala lanzó en Buenos Aires en 1947, Francisco José Martín afirma que «En propiedad, la deuda de Realidad no es con Ortega, sino con Revista de Occidente» (Martín, 2013, 172). Ahora bien, algo parecido se puede decir de Ayala: la deuda no es con Ortega (a pesar de haber estado personalmente vinculado a él), sino con sus ideas y con su espíritu. Ayala es orteguiano pero no es un clon de Ortega. Y orteguiano implica un horizonte posiblemente más abierto que Ortega: lo que me propongo aquí es trazar continuidades en el sentido más amplio posible. La tesis que

Recibido: 20/05/2019. Aceptado: 21/07/2019.

* Este trabajo forma parte de un proyecto de investigación financiado en el año 2017 por la Fundación Francisco Ayala de Granada.

** Investigador del GEXEL-CEDID de la Universidad Autònoma de Barcelona (email: alessiopiras.83@gmail. com). Sus líneas de investigación son el exilio literario y filosófico republicano español, con enfoque particular en las figuras de Max Aub y Francisco Ayala. Entre sus publicaciones más relevantes se incluye la edición y el estudio introductorio de Tranformaciones. Escritos sobre sociedad y política en España, 1961-1991 (Ayala, 2018) y el artículo «El epistolario Aub/Barral. Un testimonio de la España franquista», El correo de Euclides 12, pp. 127-135. 
trataré de demostrar es que Ayala no se limita a recoger el magisterio de Ortega, sino que lo actualiza, mejora, desarrolla y, finalmente, lo hace suyo. De orteguiano a ayaliano, se podría casi decir. Pero sin que en lo ayaliano se agote y comprenda todo lo que lo orteguiano (o el orteguismo) implica y supone.

De hecho, me ocuparé aquí de una minúscula parte del legado orteguiano en las ideas de Francisco Ayala, articulado en dos ejes fundamentales: la política y el papel del intelectual en la sociedad.

Los dos ejes están estrechamente vinculados entre sí. De alguna manera, sería imposible ser un pensador del ámbito político sin mantener un firme compromiso con la sociedad en la que se vive y de la que se habla. Tal vez al pensador sobre asuntos políticos le tocan las mismas cadenas que atan a quien la política la practica en los parlamentos y en las administraciones locales: no puede permitirse el lujo de la soledad. Al igual que un político sin electores es un político acabado, un pensador político sin lectores está condenado a ser la sombra de sí mismo, a mirarse en un espejo sin salir de su cuarto de espadas.

En lo político el intelectual orteguiano ${ }^{1}$ recoge el principio de no imponerse cadenas ideológicas, de no someter las ideas al dogma de cualquier color y bando. La libertad como responsabilidad y bien supremo. En estos raíles deja que las ideas avancen y se integren en un diálogo constante y perpetuo con la realidad, que no es algo fijo e inmutable, sino que es un continuo devenir que no se ajusta a las barreras y los compartimentos estancos de las ideologías y las religiones. En esta praxis, el intelectual orteguiano asume un compromiso con la sociedad preciso, que es el de proporcionarle siempre un punto de vista pulido y lo más objetivo posible, fundamentando sus conclusiones en el estudio, análisis y observación del mundo real, de la sociedad en la que se mueve. Rehuyendo de las utopías y decidiendo, por esto, la mayoría de las veces, dirigir sus palabras a una minoría, la misma a la que Juan Ramón Jiménez (2000) dedicaba su Segunda Antolojía poética en 1918.

\section{2. ¿Qué significaba ser un intelectual orteguiano en la Transición?}

El periodo histórico conocido como Transición sufre una indefinición temporal, debido al hecho de que los cambios en la sociedad española fueron tantos y tan rápidos que cada uno de ellos podía tener el valor de marcar un antes y un después definitivo. Por esta razón a la hora de hablar de uno de los intelectuales más destacados de esta contingencia, es debido aclarar cuál es mi perspectiva sobre la Transición democrática española.

Desde un punto de vista jurídico stricto sensu la Transición es el periodo que va de la muerte de Francisco Franco en noviembre de 1975 al referéndum constitucional del 6 de diciembre de 1978. O sea, el lazo temporal en el que se disuelve el Estado franquista

1 Una cartografía del universo orteguiano no ha sido realmente trazada. En este contexto me limito a añadir los nombres de María Zambrano, en representación del exilio, y el de Julián Marías, en representación del interior. Con matices, representan dos salidas diferentes del orteguismo, prueba de su fecundidad y pluralidad. Por otra parte, es bastante curioso el hecho de que Francisco Vázquez García en su mapa filosófico de la transición no incluya abiertamente el legado orteguiano y tampoco incluya a Francisco Ayala entre los filósofos de la época. Si por un lado es verdad que el granadino ha sido un pensador sui generis, debería ser innegable su adscripción a los filósofos políticos de este periodo, siendo tal vez el que más ha contribuido en la reflexión e interpretación del momento y del inmediato futuro. 
y se crea el Estado democrático. Sin embargo, lo jurídico no puede ser siempre categoría histórica, política o social. De hecho, para entender cuándo acaba la Transición habría que preguntarse cuándo España es efectivamente una democracia liberal, abierta y plenamente integrada en el panorama internacional, tanto formal como sentimentalmente.

Al mismo tiempo, la muerte del dictador no ha cambiado del día a la noche las exigencias y peticiones de una sociedad entera. Sostener que la Transición empieza el 21 de noviembre de 1975 sería, además de reduccionista, injusto. El mismo Ayala (2018, 127-129) subraya en la primera edición de 1965 de España, a la fecha que la sociedad española ya había empezado a moverse, ya había puesto en marcha una demanda clara y sin ambigüedades de mayor abertura y democracia. El granadino, es más, identifica en el Plan de Desarrollo de 1957 y en la consiguiente apertura económica, el primer paso hacia una evolución que habría desembocado en la liquidación del régimen franquista y su suplantación por una democracia liberal $(2018,138)$. Esto se debe a la indudable mejora de las condiciones de vida de las clases obreras y medias españolas, que han vuelto a tener conciencia de su sitio en el mundo y, sobre todo, de dónde iba Europa por aquel entonces. La oposición interna ya no era un asunto reservado a los vencidos, sino que los hijos de los vencedores tomaron partido junto a ellos y la ola de descontento junto a la demanda de libertad crecieron de forma paralela a la economía. Esta relación, bien subrayada por Ayala $(2018,132-134)$, sigue siendo menospreciada y considerada de segundo orden en el debate en torno a la Transición ${ }^{2}$. Retroceder el comienzo de este periodo y ampliar, de esta manera, el horizonte temporal permitiría

2 La posición de Ayala, y el marco interpretativo dentro del cual lee la realidad española, está arraigado en la perspectiva sociológica que ya desde los albores de la actual democracia, intentaba enfocar la Transición con un horizonte más abierto -véase, por ejemplo López Pintor (1981) y, más reciente pero igualmente relevante, Santos Juliá (1994)-. Este marco no rechaza a priori las interpretaciones de otro signo, explicadas con eficacia por Francisco Vázquez $(2009,5)$ : «Se ha hablado de "evolución pactada" y de "ruptura pactada"; unos han pretendido dar cuenta del fenómeno viéndolo como consecuencia directa del proceso de modernización económica y de renovación social [...]. Otros rechazan este argumento tildándolo de economicista y hacen hincapié en la presión ejercida por la oposición antifranquista, especialmente por la contestación obrera, estudiantil e intelectual». Al mismo tiempo, Juan Pecourt subraya que «Tanto las interpretaciones políticas como las económicas [de la transición], en sus versiones más crudas, muestran tendencias claramente reduccionistas» (2008, XII). Asimismo, Pecourt agrega (id.) que para entender la complejidad de este periodo es imprescindible estudiar los contornos de la inteligencia española y lamenta la escasez de investigaciones en este sentido. Baby (2018, 21) habla abiertamente de pactos políticos, sellados la mayoría de las veces oralmente, entre tres partes bien precisas: las oposiciones, los franquistas reformistas y los inmovilistas. La estudiosa francesa subraya que «la transformación del Estado franquista en un Estado democrático obedece a un conjunto de reformas paulatinas que no implican una ruptura radical con la legalidad anterior, simbolizándose la continuidad de los hombres y las instituciones mediante la presencia en la cima del Estado de un monarca que el proprio Caudillo había designado sucesor». Esta interpretación la considero acertada y no es excluyente, sino que manifiesta la consecuencia de la evolución de la sociedad española que se había producido a lo largo de las dos décadas que precedieron la muerte del Dictador y que Ayala cristalizó en una serie de ensayos re-editados con el título de Transformaciones. Escritos sobre política y sociedad, 1961-1991 (Ayala, 2018). Finalmente, cabe tener en cuenta el concepto de "larga Transición” o "Transición cultural” cuyos orígenes se puede remontar a los años 50 y que, entre otros, desgranan Olga Glondys y Giulia Quaggio (2017: 2918-2924). Este concepto es particularmente relevante a la hora de sustentar la idea ayaliana de una Transición con horizontes temporales anchos y que describiría mejor la evolución que se produjo en el mismo seno de la sociedad española a partir del final de los años 50 y comienzo de los 60. Glondys y Quaggio subrayan la importancia de la Tercera España, «la de la reconciliación y difícil consenso entre los vencedores y los vencidos, con sus respectivas narrativas culturales» (Glondys y Quaggio, 2017: 2919), de la que Francisco Ayala fue protagonista. 
ver con mayor perspectiva los movimientos estudiantiles, obreros y de la burguesía liberal, devolviéndole el papel que, en la realidad, han tenido para que la sociedad española diera los pasos necesarios para estar preparada para un proceso transitorio, aunque defectuoso y criticable, pacífico.

Sin embargo, si se ha asumido casi por defecto que la Transición empieza con la muerte de Franco, diferentes y más variadas son las opiniones sobre cuándo habría acabado. No es este el momento ni el lugar para decidirlo, pero lo que sí es importante para mis objetivos es dejar claro que a la hora de hablar de Transición no me refiero simple y llanamente a lo jurídico, sino a una época que va desde los años 60 y se extiende hasta, por lo menos, la mitad de los 80: solo de esta forma, creo, sin la presunción de tener la razón, es posible tener constancia de la complejidad e inevitabilidad de un proceso demasiadas veces puesto en tela de juicio, o alabado épicamente, de forma superficial, ideológica y dogmática 3.

Dicho esto, podemos avanzar en nuestro recorrido y ver qué significaba ser intelectual en un momento histórico tan delicado y marcado por un cambio político y social tan contundente. Este apartado podría ocupar no solo un artículo entero, sino un libro. O una tesis doctoral. Por eso, ruego se me disculpe la síntesis y superficialidad de mi aproximación. Remitiré, para mayores detalles, al artículo de Paul Aubert «Teoría y práctica de la Transición: el papel de los intelectuales», que considero un punto de partida imprescindible, y al libro de Juan Pecourt Los intelectuales y la transición política: un estudio del campo de las revistas políticas en España.

Aubert sostiene que a partir de la muerte de Franco se requiere a los intelectuales que vuelvan a desarrollar su función de proporcionar claves de lectura del presente y una visión del porvenir más inmediato, en un proceso transitorio que, como señala Aubert $(2016,128)$, acabó siendo constituyente. Hay que reconstruir la razón: cuatro décadas de Franco han conllevado que el intelectual llegara a ser casi irrelevante ${ }^{4}$.

3 Me refiero aquí tanto a los partidarios del relato épico, como a los detractores más endiablados. A este próposito Carme Molinero y Pere Ysàs (2018, 243-285) desmontan ambos relatos y, lo que es más importante, advierten al lector del uso político que se hizo y se hace de ambas lecturas distorsionadas para legitimar discursos y conductas que, de otra forma, no tendrían justificación. En la misma línea se pone Santos Juliá (2017, 13-16) cuando escribe que en este siglo XXI cuando se habla de la Transición muy a menudo no se está hablando de historia, de un acontecimiento histórico, sino de política, de la política del presente. De esta manera, la Transición perdería su significado y su lectura resultaría distorsionada e incorrecta. Asimismo, hay que considerar que España entra en la OTAN en 1982 y en la UE el 1 de enero de 1986. La adhesión del país a dichos tratados internacionales, de manera particular el segundo, supone un cambio social de enorme impacto, ya que a partir de entonces los Gobiernos tienen que encauzar sus políticas fiscales, industriales y financieras en pautas precisas y establecidas en un ámbito supranacional para garantizar la convivencia en todo el continente europeo.

4 Esto no significa que la figura del intelectual público no existiera antes de la muerte de Franco. Como ya señalado anteriormente, la perspectiva intelectual sobre la Transición permite ensanchar el horizonte temporal de esta última. Lo que aquí quisiera remarcar es que hasta la muerte de Franco, es decir hasta el final de la Dictadura, el impacto de la figura del intelectual público era, en la mayoría de los casos, reducido a una élite. Como señalado de forma casi pictórica por Francisco José Martín: «Más que las ideas y la crítica de oposición al régimen, importantes sin duda, en el paulatino socavamiento de la mentalidad franquista pesaron más las turistas nórdicas en toples correteando por las playas de Málaga o Alicante y el espíritu desenfadado y alternativo a las formas tradicionales de compromiso que acompañaba al despliegue de la nueva música pop y sus conciertos. Era algo que afectaba a la raíz misma de las formas de vida dominantes» (Ayala, 2018: 12-13). Fue solo después de recuperada una convivencia liberal y sin censuras que el intelectual ha podido tener la ocasión de una audiencia masiva y, por eso, ser de alguna forma influyente y relevante. 
Con la muerte del dictador, la recobrada libertad de expresión, la vuelta de los exiliados y el fin de la clandestinidad para muchos opositores, se multiplican las tribunas desde las cuales un intelectual puede lanzar sus reflexiones y, en apariencia, ser influyente en la circunstancia en la que se mueve. Se trata de revistas y diarios de todo color político que reclaman democracia y en cuyas columnas se debate sobre qué forma y aspecto deberá de tener ${ }^{5}$. Algunas de estas realidades fueron de pura contingencia, es decir, que agotaron su razón de ser con la Transición misma, como por ejemplo Triunfo, que se convirtió en referente de opinión política en los años 60 y que perdió su función opositora al faltar el objeto mismo de oposición: Franco ${ }^{6}$. Otras, como El País, lograron estabilizarse heredando la batalla de convertir la cultura en vector de militancia antifranquista y pro-democrática. Se restablece en pocas palabras la normalidad de un debate de ideas en torno a la res pública que debería tener el objetivo de explicar la realidad y desvelar, cuando es el caso, los engaños del poder. Porque el hecho de que el poder sea democráticamente elegido no le exime de un análisis crítico. Sin embargo, los años de la Transición corresponden también a los años en que los grandes relatos que sustentan las ideas se vienen abajo, o, por decirlo de otra manera, es esta la época del ocaso de las ideologías, como escribió en varias ocasiones el mismo Francisco Ayala. El ocaso de las ideologías deja a los intelectuales huérfanos de un corpus de ideas, de uno u otro signo, que sustente su discurso. Esto produce inevitablemente la fragmentación y la personalización del debate político que ya no se aglutina alrededor de un marco ideológico definido y reconocible, provocando en algunos casos una sensación de desorientación. Las ideologías construyen mundos teóricos y utópicos, que en la mayoría de los casos se alejan de la realidad efectiva. El riesgo es que el intelectual condicione su mirada y su punto de observación con el prisma ideológico hasta el punto de no ser capaz de dar una interpretación del mundo que le rodea coherente y realista. Por ello, al faltar el escudo de las grandes ideologías utópicas, el intelectual de aquella época debe enfrentarse con una realidad posmoderna, despolitizada y acostumbrada a referencias que ya no le valen.

Aubert subraya $(2016,149)$ que Ayala se situaba fuera del esquema clásico del intelectual de izquierdas antifranquista y simpatizante comunista. Sus conclusiones se fundamentaban en un análisis y estudio pragmático de la realidad española en el contexto europeo, heredando un método de estudio que había desarrollado en su profesión de sociólogo y que le permitía prescindir del relato ideológico para basarse únicamente en la realidad que observaba. Con un horizonte más amplio del español, ya en los años 60 el granadino estaba convencido de que el proceso de Transición se habría llevado a cabo sin rupturas ni grandes enfrentamientos sangrientos. Esta era la posición de Ayala, que deriva de su decenal filiación liberal y que choca frontalmente con la posición más intransigente de la oposición marxista, que concibe la Transición no como tal, sino como ruptura neta con el pasado franquista. Esta opción era inviable porque el mundo que dibuja el marxismo ha sido, en opinión de Ayala, derrotado por la misma Historia (Ayala, 2018: 149).

5 Para un estudio completo de las revistas y publicaciones que se ocupaban de política en la época de la Transición, véase Juan Pecourt (2008).

6 Muy enfáticamente, Aubert $(2019,139)$ apunta que ni Triunfo ni Cuadernos para el diálogo pudieron sobrevivir al triunfo de las mismas ideas que había propugnado. 
Hay que añadir, tal y como subraya Moreno Pestaña $(2012,295),{ }^{7}$ que el legado orteguiano fue el que más padeció el olvido durante los casi 40 años de dictadura. Es decir, que los intelectuales discípulos de Ortega no tuvieron más opciones que el exilio (inclusive interior) frustrante, a pesar de algunas excepciones ilustres como Julián Marías. Por lo tanto, ser un intelectual orteguiano en la Transición coincidía de forma casi paradójica con la condición de fiel in partibus infidelium que ya Ortega y Gasset $(2008,11)$ señalaba en las Meditaciones del Quijote como condición peculiar del pensador en España.

En el contexto político, social y filosófico que se acaba de describir, que por un lado requería a los intelectuales que marcaran las pautas morales e ideológicas del nuevo Estado, y por otro coincide con un cambio en la función del intelectual en la sociedad, se evidencia la desaparición de esta figura tal y como Ortega la había en cierta manera definido. Es más, Francisco Umbral en 1983, como recuerda Aubert (2016, 149-150), lamenta la postura esencialmente apolítica de los intelectuales del exilio de vuelta a casa, que en cierta manera eran los que habrían tenido que heredar la tradición intelectual liberal y en los que los intelectuales del interior reponían grandes expectativas. Ayala pide explicación a Umbral de su comentario y el escritor le contesta con una carta de asombroso desencanto ${ }^{8}$. En esta conyuntura de Transición, Ayala logró con cierto pragmatismo encauzar el magisterio de Ortega en una praxis intelectual que tal vez no haya realizado nada material, pero que por lo menos ha sabido delinear el futuro inmediato de España. Este proceso, sin embargo, empieza ya en pleno exilio cuando Ayala decide empezar a volver, ver con sus ojos y tocar con sus manos la realidad española9.

\section{Ayala, intelectual orteguiano de vuelta a casa}

En un conocido artículo de 1949, Ayala $(2007,193)$ se preguntaba: «Yo, español en América, ¿para quién escribo?». La respuesta que el granadino se da, en el curso de su texto, dando vueltas al tema del papel del intelectual en la sociedad, constituye el fundamento mismo en el que Ayala ha basado toda su actividad intelectual: a pesar del exilio y del olvido impuesto, nunca ha dejado de escribir por y para España y los españoles, que eran y son su público de referencia, a pesar de la universalidad del mensaje de la gran mayoría de sus

7 Véase también sobre este mismo tema Valera (1984) y Sesma Landrín (2001).

8 En su carta, Francisco Umbral escribe a Ayala que «ustedes fueron nuestra vida durante muchos años y, ahora que están aquí, apenas emergen ustedes (por decisión personal, claro, y raramente colectiva) de los suplementos literarios». La carta se conserva en la Fudanción Francisco Ayala de Granada.

9 Tal y como recuerda Aubert (2016, 129), Francisco Ayala llegó a compartir mesa con Manuel Fraga el 1 de julio de 1963. En dicha ocasión, el granadino le aconsejó al Ministro que Franco se quedara con el encargo de Jefe de Estado y que se nombrara un Presidente de Gobierno, para separar formalmente el poder Ejecutivo de las funciones representativas del Estado. Este, para Ayala, era el primer paso hacia la fragmentación del poder franquista y la disolución del estado dictatorial. El consejo no fue tenido en cuenta por Fraga, que, de hecho, se opuso a la Ley Orgánica del Estado de 1967 que separaba la jefatura del Estado del Gobierno de la Nación en los títulos II y III. El rechazo de Fraga para este proyecto está breve y eficazmente resumido por Gallego (2008, 9-17), el cual hace remontar el proceso de transición al momento en que esta parte de la Ley Organica de 1967 se pone en práctica, es decir en 1973, cuando Francisco Franco nombró Presidente del Gobierno Luis Carrero Blanco. Como es bien sabido, este mismo año Carrero Blanco es asesinato por ETA y, en su lugar, se nombra Presidente del Gobierno a Carlos Arias. 
trabajos y a pesar de afirmar que escribía en ese 1949 «Para todos y para nadie. [...] Nuestras palabras van al viento: confiemos en que algunas de ellas no se pierdan» (Ayala, 2007, 207).

Con el regreso a España, es consciente Ayala de que la situación poco cambia. La prueba la tenemos en el mismo artículo de 1949 en el cual afirma que «En resumidas cuentas, todo el que no sea un resuelto partidario del gobierno atrae la sospecha de pertenecer, dentro de la nación, al partido nefando e impreciso de la antipatria» $(2007,206)$. El intelectual, tal y como lo concibe Ayala, nunca es partidario resuelto del gobierno y, en cierta forma, siempre vive una forma de exilio, según donde físicamente se encuentre. Es esta la condición primordial del intelectual que deriva directamente del magisterio orteguiano, como ya he mencionado, de pensador in partibus infidelium. Y es este magisterio lo que determina el cauce de la actividad intelectual ayaliana a lo largo de su vida y en particular después de haber regresado definitivamente a España.

El mismo Francisco Ayala proporciona las coordenadas de su relación con Ortega y Gasset en 1983, cuando, con motivo del centenario del nacimiento del maestro, escribe:

(...) hacia 1925 o 1926, (...) empezaron a aparecer en el diario El Sol los ensayos que compondrían La rebelión de las masas, donde está descrito con lúcida profecía lo que este fenómeno vendría a cumplir del modo más espectacular y más atroz; lo que desde entonces, no ha cesado de desplegarse en maneras diversas y lugares distintos de nuestro mundo. Así, el libro de Ortega (...) presenta una actualidad inmarcesible, independientemente del momento en que fuera escrito y las concretas e inmediatas circunstancias sobre las que el autor apoyara su observación de una realidad en marcha. (...) la presencia en el terreno político de las masas que asombrarían y aterrorizarían al mundo ni se había comenzado a manifestar, ni era apenas previsible; y ahora, a la vista de ello, tiene que admirarse la gente, en España y fuera de España, de la perspicacia casi adivinatoria con que Ortega formuló hace cincuenta años el análisis y el pronóstico de lo que se nos venía encima. (2013, 354-355)

Las palabras de Francisco Ayala, además de subrayar la universalidad del legado orteguiano $^{10}$, representan una declaración muy clara de una deuda intelectual que el granadino contrajo en sus años juveniles con Ortega. Y más, un magisterio, el del filósofo, que Ayala recoge y acoge, modula y personaliza, para nunca abandonarlo, aunque sí matizarlo con los años. Creo que no hay que insistir en lo acertado que es declarar la actualidad de un texto como La rebelión de las masas, al igual que el 1 de febrero de 1994 José Luis Abellán ${ }^{11}$, en su columna del El País, trajo a cuenta España invertebrada para advertir del peligro de los nacionalismos (tanto español como vasco y catalán), en la época tan solo una velada amenaza, hoy un problema acuciante que ha paralizado la actividad legislativa del Parlament catalán de los últimos años y cuyas recaídas no tenemos exacta percepción de la intensidad que puedan tener.

10 Si aceptamos la definición que de un clásico proporciona Italo Calvino (1992), es decir un texto que no tiene barreras temporales y espaciales y cuyo mensaje siempre es válido en cualquier tiempo y época, La rebelión de las masas es a su vez un clásico de la ensayística en lengua española y un texto ejemplar en la confluencia entre filosofía y sociología, cauce este último en el que se mueve el mismo Ayala.

11 El artículo de Abellán se puede leer en la hemeroteca digital del periódico: <https://elpais.com/diario/1994/02/01/opinion/760057207_850215.html> (última consulta el 1 de abril de 2019). 
La deuda de Ayala arraiga precisamente en los años en que Ortega escribía los artículos que iban a componer La rebelión de las masas. Como bien sabemos en esa época el joven granadino se integra a la tertulia de la Revista de Occidente y toca con la mano el pensamiento político y social que vertebra el célebre ensayo. El concepto de hombre-masa, que se escapa de cualquier categorización social y económica, y el consecuente papel que Ortega y Gasset encomienda a las élites, esas minorías selectas, que plasman sus ideas alrededor de la razón vital ${ }^{12}$, constituyen las bases y los fundamentos intelectuales del futuro novelista, sociólogo y filósofo Francisco Ayala. Es este el legado de Ortega que sustenta la obra político-social de Ayala y que le confiere excepcional coherencia, continuidad y poder casi adivinatorio, cuando ya en la primera mitad de los años 60 veía como única salida del franquismo una Transición pacífica que desembocara en una monarquía parlamentaria en un contexto democrático liberal.

A la vuelta de su exilio, Ayala pone en marcha una praxis intelectual exquisitamente orteguiana. Es más, esta praxis ya se podía percibir a lo largo de su destierro, cuando, a partir de los años 60, el granadino empieza a viajar a España porque para poder escribir, opinar y aportar soluciones necesitaba ver las cosas. Es esta una deuda que Ayala atribuye a su trabajo académico de sociólogo. De estos viajes surge la primera edición de España, a la fecha, texto sobre el que volveremos más adelante. La praxis intelectual Ayala no la entiende única y solamente vinculada a la esfera académica. Rechaza, como Ortega, encerrarse en su Torre de Marfil y decide bajar a la calle, ser un escritor público, como afirmará en $1990(2013,17)$. Se da cuenta de que la única manera para que su voz pueda de alguna manera tener peso, para que su formar parte de una minoría selecta pueda tener sentido, es asegurarse una plaza pública. Al igual que en los años 20, la España de la Transición era una tierra de infieles para el intelectual, el cual «estaba llamado a predicar, y que debía predicar a la intemperie, en la plaza pública, en las páginas del noticiero cotidiano» (Ayala, 2013: 358). Estas palabras las dedica Ayala a Ortega, pero tienen relevancia para el mismo autor granadino. Por lo tanto, empieza a publicar con frecuencia en las tribunas de Informaciones y de El País. Desde las columnas de este último lanza cinco largos artículos que vertebrarán la segunda edición de España, a la fecha, publicada en 1977. Creo que es bastante evidente que el recurso de utilizar un periódico para "estrenar" las piezas que van a componer un ensayo es de clara raíz orteguiana ${ }^{13}$.

Con respecto a los contenidos, en cambio, la deuda de este texto es más bien con España invertebrada: ¿qué era el ensayo de 1921, sino el intento de poner un punto sobre la actualidad de España en la época, individuar sus dolencias y proponer una vía para encontrar la cura? Que es bien diferente de indicar cuál es esta cura; de hecho, el papel del intelectual no es cuidar al enfermo, sino dar al médico (el político, en este caso) las herramientas para hacerlo.

12 En el mismo texto citado, «Ortega y Gasset: su imagen, su estilo», Ayala escribe a propósito de la razón vital: «(...) procura un equilibrio de razón y vida que, contrapuestas como lo estaban en el pensamiento de Unamuno, se integran ahora para hacer de aquélla una función de ésta, y por cierto la que sería función principal en la peculiarísima vida humana» (Ayala, 2013: 359)

13 No ha de extrañar que a la prensa escrita Francisco Ayala dedique su discurso de entrada en la RAE, La retorica del periodismo. 
Lo que escribe Ayala con referencia a la esfera política y social tiene como punto de partida una posición despojada de ideología y que se sustenta en una profunda conciencia liberal ${ }^{14}$. Ayala actualiza durante toda su vida el discurso liberal orteguiano que, en cierto momento, se había estancado en los pantanos de la Historia de Occidente. En el «Prólogo para franceses» de 1937 de La rebelión de las masas, Ortega $(1998,135)$ no esconde que la democracia liberal, en la que bajo el amparo de la ley las minorías podían actuar y vivir, había dejado paso a «una hiperdemocracia en que la masa actúa directamente sin ley». Cuatro décadas y media más tarde, en 1981, en el famoso artículo «¿Libertad, para qué?», Ayala avisa de que la democracia solo es el sistema menos malo, pero «el que mejor garantiza la convivencia general, aquel en que la autoridad, sin abdicar de sí misma, reduce a lo indispensable la coacción del poder público, permitiendo así que cada cual, según el propio talante, se edifique su propio paraíso o su propio infierno privado» (Ayala, 2013: 140). La democracia liberal es el sistema que mejor garantiza la menor intervención del Estado en la vida del individuo, al que se garantiza el máximo desarrollo de sus aspiraciones y propósitos y en el que puede gozar del don supremo de la libertad. Sin embargo, la libertad es tal porque está reconocida y limitada por el Estado liberal, y «comporta una responsabilidad exigente en grado sumo» (Ayala, 2013, 139). Es este un punto fundamental del pensamiento liberal de Ayala porque remite directamente a la razón vital orteguiana y, en concreto, a $L a$ rebelión de las masas.

Cabe preguntarse en qué se evidencia esta «responsabilidad»: en el hecho de que ejercer la libertad significa decidir y decidir significa en última instancia vivir. Tal y como escribía Ortega $(1998,163)$ : «Vivir es sentirse fatalmente forzado a ejercitar la libertad, a decidir lo que vamos a ser en este mundo. Ni un solo instante se deja descansar a nuestra actividad. Inclusive cuando desesperados nos abandonamos a lo que quiera venir, hemos decidido no decidir». «¿Libertad, para qué?» solo es uno de los ejemplos de cómo Ayala actualizó el discurso político de Ortega sin rechazarlo nunca. Hijo de otro tiempo, entre otras cosas Ayala ya no considera América como la hijastra de Europa y hace de su experiencia de vida en Estados Unidos un valor añadido a su reflexión sobre la democracia liberal. Tal vez, fue precisamente un excesivo ensimismamiento en Europa lo que no le permitía a Ortega ver en América una posible salida del infierno de finales de los años 3015. En la relación con América reside una de las más evidentes diferencias entre maestro y discípulo y, sobre todo, uno de los ámbitos en que mejor se aprecia el alcance del magisterio orteguiano y sus potencialidades como herramientas para interpretar el tiempo que se está viviendo ${ }^{16}$.

14 En el prólogo al VI volumen de las Obras completas de Ayala, Santos Juliá (Ayala, 2013, 17-18) recuerda el legado de otro pensador liberal español, tal vez el primero de su estirpe, Mariano José de Larra.

15 El eurocentrismo ciego de Ortega y Gasset constituye uno de sus límites más evidentes y ha proporcionado a sus detractores un espacio de crítica a priori ampliamente disfrutado (véase el demoledor artículo de Faber (2015)). Sin embargo, en la época en que Ortega escribía La rebelión de las masas, ya era un clásico casi universal de las ciencias políticas el ensayo de Toqueville (1993) sobre EEUU y la calidad de la democracia americana, con sus estrechos vínculos con el pensamiento de Stuart Mill (1970) contenido en Sobre la libertad. Esto para decir que la superioridad moral de Europa era algo indudablemente anacrónico y que ha limitado enormemente el horizonte de Ortega, pero no el alcance del orteguismo, como demuestra el mismo Ayala.

16 Son numerosas las columnas que Ayala, regresado a España, dedica a EEUU con el claro objetivo de dar a conocer los mecanismos (y los límites) de uno de los regímenes democráticos más sólidos del mundo. Véase Ayala (2013). 
Asimismo, la experiencia académica de sociólogo, el exilio vivido sin grandes nostalgias y un sentido de la realidad fuera de lo común, hacen que el granadino esté perfectamente instalado en su tiempo, que sea hombre de su tiempo y pueda individuar los engaños y las trampas del presente para poder guiar a sus lectores. Entiende que el único sistema que puede garantizar progreso y bienestar es la democracia liberal, que cualquier otra alternativa conocida hasta la época solo constituiría un paso atrás. De hecho, nunca aboga por una vuelta al statu quo de 1936: el problema para Ayala no es entre República y Monarquía, sino en la recuperación de los valores y principios intelectuales más nobles del periodo republicano para adaptarlos al presente, o para que sean el punto de partida del nuevo Estado democrático liberal. Esta mirada, que implica un diálogo entre pasado y futuro, que tiene en el pasado una referencia y en el futuro un objetivo, es a mi modo de ver un rasgo evidente de la razón vital de Francisco Ayala porque concibe el futuro como oportunidad y el pasado como recurso constructivo. De hecho, en la edición de 1965 de España, a la fecha, el granadino se hace premonitor del futuro de España, imaginando y avisando de cuál sería el único camino posible para que el país recuperara la democracia y se integrara en la Comunidad Europea.

Finalmente, merece la pena, si bien brevemente, abordar el tema de la integración de España en Europa. Ortega ha sido uno de los pensadores que más tinta ha dedicado a profetizar una única entidad política que incluyera los viejos Estados nacionales europeos, una entidad en la que la diversidad entre los pueblos se respetara en la base de un sentimiento común de ciudadanía continental. Las páginas más contundentes que dedica a Europa, Ortega las escribe en el periodo de entreguerras, es decir, después de la gran tragedia continental de 1914-1918, en la que España no participa, pero que el filósofo percibe como suya también. Ortega ve en la integración de España en Europa la única vía para que el país salga de su secular aislamiento y particularismo, del cual la neutralidad en la Primera Guerra Mundial fue un ejemplo. Sin entrar en detalles, se puede afirmar que Ortega ha sido uno de los padres de la actual Unión Europea, aunque su visión fuera más ideal que práctica ${ }^{17}$.

Ayala recoge el legado europeísta orteguiano muy tempranamente, como atestigua la conferencia que el 14 de enero de 1931 lee en Ginebra, con el título «Sobre el punto de vista español ante la propuesta de una unión federal europea», en la que se expone la posición española frente a la propuesta de una Unión federal europea avanzada por Francia en $1930^{18}$. En ella, Ayala intenta encontrar un equilibrio entre lo que puede verse como proyecto hegemónico francés y una real oportunidad que tendrían las naciones europeas de superar su secular nacionalismo y hacer frente común reforzándose la una con la otra. De manera significativa, el granadino acaba su larga intervención citando precisamente a Ortega y Gasset:

17 Véase como fuente primaria Ortega y Gasset (2015) y como fuente crítica: Sebastian Lorente (1994), Fioraso (2005) y García Fernández (2017).

18 La conferencia está publicada en Ayala (1931). Se leyó en el marco de los trabajos de la Asamblea de la Sociedad de las Naciones de 1931, llamada a debatir, entre otras cosas, el Memorandum sur l'organisation d'un régime d'union fédérale européenne presentado en el mayo de 1930 por el Ministro de Exteriores francés, Aristide Briand. En el memorando los 27 Estados europeos miembros de la Sociedad de las Naciones reconocen la necesidad de constituir «entre peuples d'Europe, d'une sorte de lien fédéral qui établisse entre eux un régime de costante solidarité» (9). A pesar de no haberse concretado en la década de los 30, el memorando de Briand fue retomado y utilizado como punto de partida en la segunda posguerra mundial para la creación de la CEE (hoy UE), que nació en Roma en 1957. 
Pues solo hemos conseguido en este trabajo brindar al público unas cuantas sugestiones acerca de las grandes directrices sobre que debe marchar la opinión y la acción española ante el Memorándum Briand para la organización de un régimen de Unión federal europea, cuyo proyecto ha de ser, sin duda, eje de la política internacional en los años venideros, y cuya decisión -según afirma en su último libro José Ortega y Gasset-, es lo único que «volvería a entonar la pulsación de Europa». (Ayala, 1931, 21)

En 1985, al hablar de Europa en el momento en que la integración de España a la CEE se lleva a cabo, Ayala supera tanto el idealismo orteguiano como sus débiles resistencias juveniles expuestas en la citada conferencia, y da una salida práctica al europeísmo que había configurado su pensamiento político en las décadas pasadas. En un artículo del 12 de junio de 1985, el granadino celebra sin eufemismos la reciente firma de los tratados y del acta de adhesión de España en la Comunidad Europea, que se hará efectiva el 1 de enero de 1986:

[...] para España la admisión a ese club ha sido, no hay duda, un hecho de gran alcance histórico, cuya importancia apenas si podemos calcular todavía, por cuanto que, sacando a este país nuestro del prolongado aislamiento y marginación en que se ha mantenido desde que perdiera la hegemonía imperial, lo sitúa otra vez en el terreno de las realidades contemporáneas. (Ayala, 2013, 920)

Esto implica que España «entra a compartir de lleno las decisiones históricas» (2013, 917), hecho de gran importancia para un país que hasta 10 años antes vivía en el más antihistórico régimen dictatorial europeo. Asimismo, Ayala ve en la adhesión de España a la Comunidad Europea la superación definitiva no solo del nacionalismo español, sino también de los nacionalismos locales, ya que el centro de las decisiones se movería de Madrid a Bruselas y, por eso, desaparecerían por completo «los recelos de imposición cultural ejercida desde el centro de la Península» (Ayala, 2013, 919). Creo que no hace falta decir que, leídas hoy estas palabras, nuestro pensador haya cometido pecado de excesivo optimismo y confianza.

\section{4. ¿Se pueden definir continuidades y rupturas con Ortega y la etapa del exilio?}

Según la muy conocida ley de la conservación de la masa, nada se crea y nada se destruye, sino que todo se transforma. El pensamiento de Ortega sobrevive al mismo Ortega, se hace orteguiano y se transforma en otra cosa por medio de sus discípulos. Entre ellos, Francisco Ayala. Más que de continuidades, habría que hablar de desarrollo y actualización, de una puesta al día de una manera de pensar e interpretar el mundo y el papel del intelectual en la sociedad. Los medios a disposición en los años 20 no eran los mismos que en los años 70 y 80 . Sin embargo, la importancia de la élite, de las minorías selectas sigue vigente. El intelectual tiene que adaptar su discurso a la Historia y a la tecnología. Era algo que Ortega en su tiempo, y Ayala en el suyo, sabían perfectamente. El granadino, por lo tanto, se puede definir como un intelectual orteguiano de vuelta a casa, por dos razones:

1) en la praxis nunca renuncia a su compromiso y a lanzar su voz en la plaza pública para iluminar el camino de sus lectores, incluso cuando sus ideas pueden encontrar el desacuerdo de la mayoría: Ayala sabe que no es un político y, por eso, puede prescindir del consenso; 
2) en las ideas: el pensamiento liberal, el europeísmo, la centralidad del intelectual y la necesidad de una interacción dialógica entre pasado y futuro son las principales marcas orteguianas en Ayala, que le permiten analizar el presente sin aferrarse al espacio cómodo y simplificador de las ideologías.

Sin embargo, él no se limita a ser portavoz o alumno diligente de su maestro: modula las ideas orteguianas, se apodera de ellas, las encaja en la nueva realidad de su tiempo y les da nueva vida. Las quita del estanco en que se habían encallado a finales de los años 30 para transformarlas y de esta manera adquiere, Ayala, su propia voz. Una voz de extrema coherencia, adherida a la realidad y capaz de una lucidez vital a veces sorprendente.

\section{Bibliografía}

Abellán, J. L. (1994), «España invertebrada. Estado de la cuestión», El País, 1 de febrero de 1994. [<https://elpais.com/diario/1994/02/01/opinion/760057207_850215.html>consultado el 1 de abril de 2019]

Ayala, F. (2018), Transformaciones. Escritos sobre política y sociedad en España, 19611991, Edición, estudio preliminar y notas de Alessio Piras, Granada: Fundación Francisco Ayala/Universidad de Granada.

Ayala, F. (2013), Obras completas vol. VI: De vuelta en casa (Colaboraciones en prensa, 1976-2005), Barcelona: Galaxia Guntenberg.

Ayala, F. (2007), Obras completas vol. III: Estudios literarios, Barcelona: Galaxia Gutenberg.

Ayala, F. (1931), «Sobre el punto de vista español ante la propuesta de una unión federal europea», Revista general de legislación y jurisprudencia, Madrid: Editorial Reus.

Baby, S. (2018), El mito de la transición pacífica. Violencia y política en España (19751982), Madrid: Akal.

Calvino, I. (1992), Perché leggere i classici, Torino: Einaudi.

Faber, S. (2015), «Biografía de un hombre masa: ¿qué le debe España a Ortega y Gasset?», Res Pública. Revista de historia de las ideas políticas, vol. 18 num. 1, pp. 227-241.

Fioraso, N. (2005), «Europa come soluzione. Europa come problema. Il pensiero politico di Ortega y Gasset», en: Marcolungo, F. L. (ed.), Identità europea e libertà, Padova: Cleup, pp. 195-206.

Gallego, F. (2008), El mito de la transición. La crisis del franquismo y los orígenes de la democracia (1973-1977), Barcelona: Crítica.

García Fernández, L. (2017), «La Europa latente de José Ortega y Gasset. Análisis y valoración de su Idea de Europa», Bajo palabra. II Época, 17, pp. 597-618.

Glondys O. e Quaggio G. (2017), «Del compromiso ideológico a la sociedad de consumo reconciliada: los intelectuales y la transición cultural española», en: González Madrid D., Ortiz Heraz M. y Pérez Garzón J. S., Actas del XIII Congreso de la Asociación de Historia Contemporánea, Cuenca: Ediciones de la Universidad de Castilla-La Mancha, pp. 2918-2924.

López Pintor, R. (1981), «Los condicionantes socioeconómicos de la acción política en la transición democrática», Revista Española de Investigaciones Sociológicas, 15, pp. 9-32. 
Martín, F. J. (2013), «Filosofía y crisis de la modernidad en Realidad», en: Castillo Ferrer, C. y Rodríguez Gutiérrez, M. (eds.): Realidad. Revista de ideas (Buenos Aires, 1947-1949), Granada: Fundación Francisco Ayala/Universidad de Granada.

Memorandum sur l'organisation d'un régime d'union fédérale européenne, Archivo de las Naciones Unidas de Ginebra [<https:/www.wdl.org/es/item/11583/>, consultado el 08/04/2019].

Molinero, C. e Ysàs, P. (2018), La Transición. Historia y relatos, Madrid: Siglo XXI.

Ortega y Gasset, J. (2017), «Vieja y nueva política», en: Ortega y Gasset, J.: Obras completas tomo 1 (1902-1925), Madrid: Taurus.

Ortega y Gasset, J. (2015), Meditación de Europa y otros ensayos, Madrid: Alianza Editorial.

Ortega y Gasset, J. (2011), España invertebrada, Barcelona: Austral.

Ortega y Gasset, J. (2008), Meditaciones del Quijote, Madrid: Revista de Occidente/Alianza Editorial.

Ortega y Gasset, J. (1998), La rebelión de las masas, Madrid: Revista de Occidente/Alianza Editorial.

Pecourt, J. (2008), Los intelectuales y la transición política. Un estudio del campo de las revistas políticas en España, Madrid: CIS.

Jiménez, J. R. (2000), Segunda antolojía poética, Barcelona: Espasa Libros.

Juliá, S. (2017), Transición. Historia de una política española (1937-2017), Barcelona: Galaxia Gutemberg.

Juliá, S. (1994), «Orígenes sociales de la democracia en España», Ayer, 15, pp. 165-188.

Sebastian Lorente, J. (1994), «La idea de Europa en el pensamiento político de Ortega y Gasset», Revista de Estudios Políticos, 83, pp. 221-245.

Sesma Landrín, N. (2001), «José Ortega y Gasset: del exilio exterior al exilio interior (1936-1955)», en: Gil Encabo F. y Ara Torralba J. C. (coords), La España exiliada de 1939: actas del congreso "Sesenta años después"(Huesca, 26-29 de octubre de 1999), Zaragoza: Instituto Fernando el Católico, pp. 651-660.

Stuart Mill, J. (1970), Sobre la libertad, Madrid: Alianza Editorial.

Valera, F. (1984), «Tránsito de Ortega por escena política de España», Cuadernos de investigación histórica, 8, pp. 203-214.

Toqueville, A. (1993), La democracia en América, Madrid: Alianza Editorial. 
